OPEN ACCESS

Edited by:

Quancai Sun,

Jiangsu University, China

Reviewed by:

Zixuan Gu,

North Dakota State University,

United States

Enbo Xu,

Zhejiang University, China

*Correspondence:

Hui-Li Wang

wangh/@hfut.edu.cn

tThese authors have contributed equally to this work

Specialty section: This article was submitted to Nutrition and Food Science Technology,

a section of the journal

Frontiers in Nutrition

Received: 12 July 2021

Accepted: 23 August 2021

Published: 23 September 2021

Citation:

Liao Q, Tao H, Li Y, XU Y and

Wang H-L (2021) Evaluation of

Structural Changes and Molecular

Mechanism Induced by High

Hydrostatic Pressure in Enterobacter

sakazakii. Front. Nutr. 8:739863.

doi: 10.3389/fnut.2021.739863

\section{Evaluation of Structural Changes and Molecular Mechanism Induced by High Hydrostatic Pressure in Enterobacter sakazakii}

\author{
Qiaoming Liao ${ }^{1,2+}$, Han Tao ${ }^{1,2+}$, Yali $\mathrm{Li}^{1}$, Yi Xu ${ }^{1}$ and Hui-Li Wang ${ }^{1,2 *}$ \\ ${ }^{1}$ Engineering Research Center of Bio-process, Ministry of Education, Hefei University of Technology, Hefei, China, ${ }^{2}$ School of \\ Food Science and Engineering, Hefei University of Technology, Hefei, China
}

The contamination of infant milk and powder with Enterobacter sakazakii poses a risk to human health and frequently caused recalls of affected products. This study aims to explore the inactivation mechanism of $E$. sakazakii induced by high hydrostatic pressure (HHP), which, unlike conventional heat treatment, is a nonthermal technique for pasteurization and sterilization of dairy food without deleterious effects. The mortality of $E$. sakazakii under minimum reaction conditions (50 MPa) was $1.42 \%$, which was increased to 33.12\% under significant reaction conditions (400 MPa). Scanning electron microscopy (SEM) and fluorescent staining results showed that $400 \mathrm{MPa}$ led to a loss of physical integrity of cell membranes as manifested by more intracellular leakage of nucleic acid, intracellular protein and $\mathrm{K}^{+}$. Real-time quantitative PCR (RT-qPCR) analysis presents a downregulation of three functional genes ( $g / p K, p b p C$, and $o m p R)$, which were involved in cell membrane formation, indicating a lower level of glycerol utilization, outer membrane protein assembly, and environmental tolerance. In addition, the exposure of E. sakazakii to HHP modified oxidative stress, as reflected by the high activity of catalase and super oxide dismutase. The HHP treatment lowered down the gene expression of flagellar proteins (fliC, flgl, fliH, and flgK) and inhibited biofilm formation. These results determined the association of genotype to phenotype in E. sakazakii induced by HHP, which was used for the control of food-borne pathogens.

Keywords: E. sakazakii, high hydrostatic pressure, biofilm, flagellar proteins, mechanism

\section{INTRODUCTION}

Enterobacter sakazakii is a motile, non-spore formation and rod-shaped Gram-negative organism. It is an emerging food-borne pathogen that is found in several foods, such as skim milk, meat, chicken skin, fruits, and cheese (1). E. sakazakii can form biofilm, which is a spatially organized dynamic ecosystem, against environmental stress and host immune surveillance mechanisms (2). It can attach to abiotic materials such as silicon, latex, polycarbonate, stainless steel, glass, and polyvinyl chloride, which results in a series of infectious diseases such as neonatal sepsis, meningitis, and brain abscess (3). E. sakazakii can survive in a wide range of temperatures from 4 to $47^{\circ} \mathrm{C}$, exhibiting substantial resistance to heating process. Edelson-Mammel et al. (4) isolated 12 Enterobacter strains from rehydrated powdered infant formula that could survive at $58^{\circ} \mathrm{C}$. Perez et al. (5) studied the effectiveness of pulsed electric field treatment on the inactivation of 
E. sakazakii, and they found that higher field strength and longer treatment time increased the inactivation. Lee et al. (6) showed that there was no regrowth of E. sakazakii in contaminated infant powder after gamma-irradiation at $5 \mathrm{kGy}$. More and more researchers are focusing on green and efficient non-thermal sterilization instead of traditional heating process to keep the sensory, nutritional, and functional ingredients of food.

High hydrostatic pressure has been demonstrated to be an effective non-thermal processing method for the pasteurization and sterilization of dairy food (7). The pressure is applied on the interior and surface of foods through liquid instead of traditional thermal treatment. The potential application of HHP to E. sakazakii inactivation is focused on the process of wet mixture treatment before spray drying and the production of a novel non-thermally treated pasteurized liquid infant milk formula. The first study on E. sakazakii inactivation by HPP was conducted by Gonzalez et al. (8) using a reference medium. Inactivation levels between 2 and $6 \log 10$ cycles were achieved. Arroyo et al. (9) reported that HHP resulted in sublethal injuries to the outer and cytoplasmic membranes in E. sakazakii. Pressure-holding time, pressure level, and food matrix also affect the inactivation of E. sakazakii (10). Sublethal injuries to the outer and cytoplasmic membranes were detected after HHP. Scanning electron micrographs indicated that cellular envelope and intracellular damages of E. sakazakii cells were apparent after 300 and $400 \mathrm{MPa}$ for $5 \mathrm{~min}$ compared with the untreated cells, and a progressive increase of injured cells with increased pressure treatment was observed. E. sakazakii was sensitive to high pressure processing treatment, and high-pressure processing treatment with $400 \mathrm{MPa}$ for $3 \mathrm{~min}$ can be used to control $E$. sakazakii contamination in milk samples (11). This article aims to determine the relationship between HHP-induced structural changes and molecular variations that occur in E. sakazakii by plate counting, fluorescence staining, SEM, cellular leakage, oxidative enzyme activity, and RT-qPCR analyses. Applying new findings in Cronobacter spp. sterilization techniques would be of great help in assuring product quality.

\section{MATERIALS AND METHODS}

\section{Bacterial Strain and Incubation Conditions}

Enterobacter sakazakii (ATCC 29544) was purchased from BeNa Culture Collection (Beijing, China). Strain activation was performed by following the instructions of the supplier. First, the activated strains stored at $-20^{\circ} \mathrm{C}$ were transferred into a test tube containing 5-ml nutrient broth (Sinopharm Chemical Reagent Co., Ltd., Beijing, China) at $37^{\circ} \mathrm{C}$ in a constant temperature incubator under 200-rpm shaking speed conditions overnight. Then, $100 \mu \mathrm{l}$ of the incubated strains were transferred in a fresh nutrient broth $(5 \mathrm{ml})$ and cultured under same conditions for approximately 4 to $5 \mathrm{~h}$ until the concentration of cells reached $10^{8}$ colony-forming unit $(\mathrm{CFU}) / \mathrm{ml}$.

\section{HHP Treatment}

The bacteria were cultured in a nutrient broth medium for $6 \mathrm{~h}$ and subjected to centrifugation at 5,700 $\times$ g for $3 \mathrm{~min}$. The cell precipitates were washed twice with phosphate-buffered saline
(PBS) and then centrifuged by following the above procedure. The pellets were resuspended in PBS $(1 \mathrm{ml})$ to a cell destiny of $10^{8} \mathrm{CFU} / \mathrm{ml}$. The HHP experimental method used in this study is described in Yamin et al. (12). The cell suspension (2 ml) was heat-sealed in sterile polyethylene (Wangshi Packaging, Hebei province, China) after exclusion of the air bubbles and subjected to 0-, 50-, 100-, 200-, 300-, and 400-MPa treatments at $25^{\circ} \mathrm{C}$ for $10 \mathrm{~min}$, with 3 -min pressurization/30-s depressurization. The HHP treatment was administered using a 3-L-capacity pressure vessel (Bao tou KeFa High Pressure Technology Co., Ltd, Bao tou, China), with water as the transmission fluid.

\section{Plate Counting Method}

Viable colonies were enumerated by plate dilution colony counting. All the treated groups of samples were serially diluted with a $0.85 \% \mathrm{NaCl}$ solution in a ratio of $1: 9$. Subsequently, the aliquot $(50 \mu \mathrm{l})$ of the cultures in solid nutrient broth was plated and incubated at $37^{\circ} \mathrm{C}$ for $24 \mathrm{~h}$. Each experiment was performed in triplicate.

\section{Intracellular Leakage Measurement}

Aliquots of $3 \mathrm{ml}$ of cell cultures exposed to different intensities of pressure were centrifuged at $4,000 \times \mathrm{g}$ for $5 \mathrm{~min}$. The supernatant containing nucleic acid was gradually subjected to filtration using a $25-\mathrm{mm}$ and $0.22-\mu \mathrm{m}$-diameter filter. Total nucleic acid content was quantified with a micro plate spectrophotometer (Infinite 200 PRO; Tecan, Mannedorf, Switzerland) with absorbance at $260 \mathrm{~nm}$.

The leakage of protein was measured by bicinchoninic acid (BCA) protein method with a protein assay kit (A045-4-2, Nanjing Jiancheng Bioengineering Institute, Jiangsu, China). One milliliter of the cell sample was mixed with $9 \mathrm{ml}$ of PBS solution $(0.1 \mathrm{~mol} / \mathrm{L}, \mathrm{pH} 7.4)$ and then centrifuged at $3,500 \times$ $\mathrm{g}$ for $10 \mathrm{~min}$, and $10 \mu \mathrm{l}$ of the supernatant was incubated with BCA buffer $(250 \mu \mathrm{l})$ at $37^{\circ} \mathrm{C}$ for $30 \mathrm{~min}$ before being subjected to measurement using a microplate spectrophotometer (Infinite 200 PRO; Tecan, Mannedorf, Switzerland) with maximum absorption at $562 \mathrm{~nm}$.

The leakage of $\mathrm{K}^{+}$was measured by following the instructions in the $\mathrm{K}^{+}$assay kit (C001-2-1, Nanjing Jiancheng Bioengineering Institute, Jiangsu, China). The bacteria cell culture was mixed with deionized water in a ratio of 1:9 and centrifuged at 2,500 $\times$ $\mathrm{g}$ for $10 \mathrm{~min}$, and then $20 \mu \mathrm{l}$ of the supernatant was precipitated with $180 \mu \mathrm{l}$ of protein deposits and centrifuged at 3,500 $\times \mathrm{g}$ for $5 \mathrm{~min}$. Fifty picoliters of the supernatant was incubated with an Na-TPB buffer $(200 \mu \mathrm{l})$ for 5 min before being subjected to measurement using a microplate spectrophotometer (Infinite 200 PRO, Tecan, Mannedorf, Switzerland) at $450 \mathrm{~nm}$.

\section{Measurement of Cellular Enzyme Activity}

Superoxide dismutase enzyme activity was estimated using a superoxide dismutase (SOD) assay kit (A001-3-1, Nanjing Jiancheng Bioengineering Institute, Jiangsu, China). All the $E$. sakazakii samples were centrifuged at $1,000 \times \mathrm{g}$ for $10 \mathrm{~min}$ and the sediments were cultured with $1 \mathrm{ml}$ of PBS $(\mathrm{pH}=7)$ to get homogenized for $3 \mathrm{~min}$; then, $20 \mu \mathrm{l}$ of the culture was mixed with $20 \mu \mathrm{l}$ of the enzyme solution and $200 \mu \mathrm{l}$ of the 
substrate solution at $37^{\circ} \mathrm{C}$ for $30 \mathrm{~min}$ before being subjected to measurement using a microplate spectrophotometer (Infinite 200 PRO; Tecan, Mannedorf, Switzerland) with $450 \mathrm{~nm}$ absorbance.

$$
\begin{aligned}
& \text { SOD inhibition ratio }(\%)=\left[\left(A_{C}-A_{B C}\right)-\left(A_{E}-A_{B E}\right)\right] /\left(A_{C}\right. \\
& \left.-A_{B C}\right) \times 100 \% \\
& \text { SOD activity }(U / \mathrm{mg} \text { prot }) \\
& =S O D \text { inhibition ratio } \times / \text { protein concentration }(\mathrm{mg} \mathrm{prot} / \mathrm{ml})
\end{aligned}
$$

Catalase (CAT) activity was measured by following the instructions in the CAT assay kit (A007-1-1, Nanjing Jiancheng Bioengineering Institute, Jiangsu, China). The cell culture was prepared as SOD procedure: All the E. sakazakii samples were centrifuged at $1,000 \times \mathrm{g}$ for $10 \mathrm{~min}$ and the sediments were cultured with $1 \mathrm{ml}$ of $\mathrm{PBS}(\mathrm{pH}=7)$ to get homogenized for $3 \mathrm{~min}$ which has been added. Then, $1 \mathrm{ml}$ of $\mathrm{NO} 0.3$ solvent and $0.1 \mathrm{ml}$ of NO 0.4 solvent were immediately added before measurement using a microplate spectrophotometer (Infinite 200 PRO; Tecan, Mannedorf, Switzerland) at $405 \mathrm{~nm}$ absorbance.

$$
\begin{aligned}
& \text { CATactivity }(\mathrm{U} / \mathrm{mg} \text { prot }) \\
& =\left(\mathrm{OD}_{\text {blank }}-\mathrm{OD}_{\text {sample }}\right) \times 271 /(60 \\
& \times \text { samplecapacity }) / \text { proteinconcentration }(\mathrm{mg} \mathrm{prot} / \mathrm{ml}):
\end{aligned}
$$

$A_{C}$ : the absorbance of control group at $450 \mathrm{~nm}$

$\mathrm{A}_{\mathrm{BC}}$ : the absorbance of blank control group at $450 \mathrm{~nm}$

$A_{E}$ : the absorbance of experimental group at $450 \mathrm{~nm}$

$\mathrm{A}_{\mathrm{BE}}$ : the absorbance of experimental blank group at $450 \mathrm{~nm}$. Protein concentration was measured by following the instructions in the protein assay kit (A045-4-2, Nanjing Jiancheng Bioengineering Institute, Jiangsu, China).

\section{SEM Analysis}

The samples were centrifuged $(5,700 \times \mathrm{g})$ for $3 \mathrm{~min}$. The sediment was mixed with $2.5 \%$ glutaraldehyde overnight at $4^{\circ} \mathrm{C}$ to fix. Then, the fixed cells were washed with phosphate buffer and dehydrated in graded ethanol solutions (50, 70, 95, and $100 \%)$, stuck to the conductive adhesive tape, coated with goldpalladium, and observed with a scanning electron microscope (X650; Hitachi, Tokyo, Japan).

\section{Fluorescent Staining Procedure}

Fluorescent dye propidium iodide (PI) was used to evaluate cell permeabilization. The HHP-treated E. sakazakii (50 and 400 $\mathrm{MPa}$ ) suspensions in phosphate buffered saline (PBS) were mixed with $50 \mu \mathrm{l}$ of the PI solution $(5 \mathrm{mg} / \mathrm{ml})$. The mixture was placed in the dark at $25^{\circ} \mathrm{C}$ for $10 \mathrm{~min}$ and then centrifuged $(5,700 \times$ $g$ ) for $3 \mathrm{~min}$ at $4^{\circ} \mathrm{C}$. The precipitate was washed with PBS twice until no excess dye was left. Fluorescence was measured with a fluorescence microscope (ECLIPSE Ti2; Nikon, Tokyo, Japan).

\section{Quantification of Biofilm Formation}

Biofilm quantification was performed by crystal violet (CV) assay. Biofilms formed in 96-well polystyrene microtiter plates after the HHP treatment. Non-adherent cells were washed softly with phosphate-buffered saline (PBS) after 12, 24, and $48 \mathrm{~h}$ of growth and fixed under $60^{\circ} \mathrm{C}$ for $1 \mathrm{~h}$. The biofilms were stained with $200 \mu \mathrm{l}$ of $0.1 \%$ crystal violet (CV) for $20 \mathrm{~min}$ and washed with $\mathrm{PBS}(\mathrm{pH}=7)$ three times until no $\mathrm{CV}$ was left. First, the biofilms were imaged using the fluorescence microscope (ECLIPSE Ti2; Nikon, Tokyo, Japan) and then dissolved in 33\% acetic acid. The OD values of each well were determined at $590 \mathrm{~nm}$ using the microplate spectrophotometer (Infinite 200 PRO; Tecan, Mannedorf, Switzerland).

\section{RNA Isolation and Real-Time Quantitative Polymerase Chain Reaction (RT-qPCR) Assay}

The cells were pelleted by centrifugation at $5,000 \mathrm{rpm} / \mathrm{min}$ for $1 \mathrm{~min}$, washed three times, and resuspended in $\mathrm{PBS}(\mathrm{pH}=$ 7). Total RNAs were extracted from E. sakazakii using RNeasy Protect Bacteria Mini Kit (QIAGEN, Shanghai, China) after the HHP treatment. The quality, integrity, and concentration of the RNA were measured. Subsequently, the RNA was reverse-transcribed into cDNA with First-Stand cDNA Synthesis SuperMix (Transgen Biotech, Beijing, China) and stored at $-20^{\circ} \mathrm{C}$, resulting in the first stands of total cDNA. The primers custom-synthesized by General Biosystems LTD (Anhui, China) are listed in Table 1. Amplification and detection were carried out using LightCycle96 Q-PCR (Roche, Basel, Switzerland). The relative expression of each gene was quantified using $16 \mathrm{~S}$ rRNA as internal control. All the samples were analyzed in triplicate.

\section{Statistical Analysis}

All the experiments were carried out in triplicate. Statistical analysis was performed using the SPSS software (version 19.0; IBM; Armonk, NY, United States). An analysis of variance was performed on the results by an independent sample test, and the data were presented as the mean values $\pm \mathrm{SD}$. A $P$-value lower than 0.05 indicated a significant difference.

TABLE 1 | Primers used for real-time quantitative PCR (RT-qPCR) analyses.

\begin{tabular}{lll}
\hline Primers & Sequences $\left(\mathbf{5}^{\prime} \mathbf{- 3}^{\prime} \mathbf{)}\right.$ & Gene \\
\hline GlpKF & TGGCGAACAACTTCCTGA & GlpK \\
GlpKR & CGCTCGGTGGTTCAATAC & \\
PbpCF & TTCGCAACTTGGCTATTCC & PbpC \\
PbpCR & AAGCGTAGTGGTGATTGG & \\
OmpRF & TGGTGCTTGATCTGATGCTC & OmpR \\
OmpRR & AGGGTTGACGGTTAGGAAT & \\
FliCF & CTTACAGCGTATCCGTGAGC & FliC \\
FliCR & GCCGTTGAATTAGCACCA & \\
FliHF & ACCTGATAAGCAGATCCAGAC & FliH \\
FliHR & TTCATCGGCGGAGACTTG & \\
FlgKF & CGTTCTGGGGCAGTCTAACA & FlgK \\
FlgKR & GACCATATCGTCGATTTCG & \\
FlglF & GATTCCTGCTGTTGCTCGTC & Flgl \\
FlglR & TCAGGCTCTGGGTGGTAAA &
\end{tabular}




\section{RESULTS AND DISCUSSION \\ Inactivation of Enterobacter sakazakii With HPP}

The extent of the inactivation of E. sakazakii exposed to the pressure treatment was assessed by plate count analysis (Figure 1A). This result revealed that the percentage of survival of the cells decreased with increase in pressure. The mean initial count of E. sakazakii in PBS was $9.39 \log \mathrm{CFU} / \mathrm{ml}$, which was slightly reduced by the $50-\mathrm{MPa}$ treatment by $0.35 \mathrm{log}$ but was significantly $(P<0.001)$ decreased to $3.11 \log \mathrm{CFU} / \mathrm{ml}$ under
$400 \mathrm{MPa}$ conditions. This showed that the organism tolerated the pressure with little effect on viability when $50 \mathrm{MPa}$ was reached. Similar results were reported by Gonzalez et al. (8) and Perez et al. (5). Inactivation levels between 2 and $6 \log 10$ cycles were achieved. Thus, 50 and $400 \mathrm{MPa}$ were used as the minimum treatment limit and significant treatment conditions for subsequent structural and molecular analyses.

Structural changes in E. sakazakii were observed by propidium iodide (PI) uptake and scanning electron microscopy (SEM). PI analysis exhibited higher permeability of HHPtreated bacterial cell membrane, since the fluorescent agent

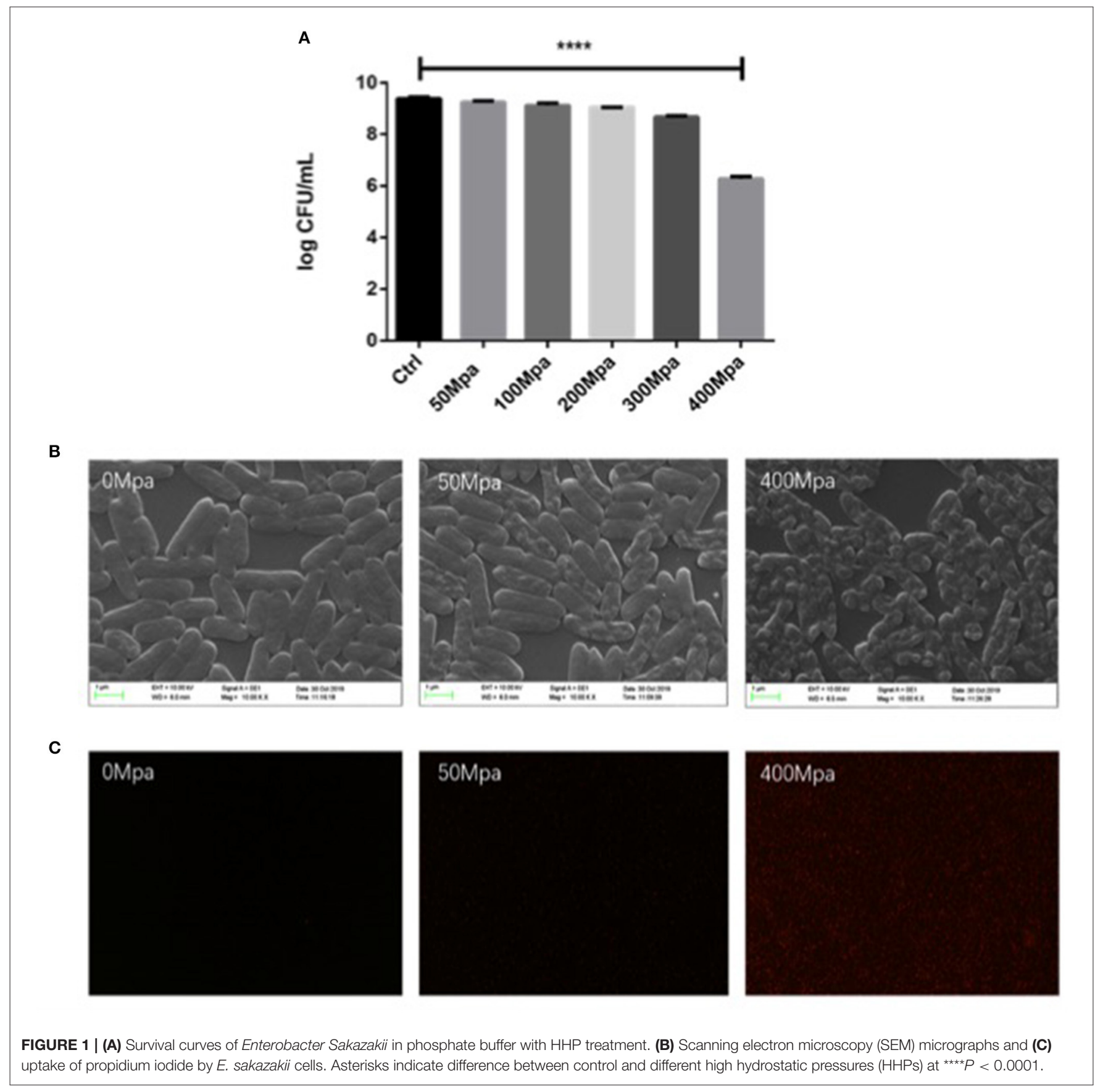



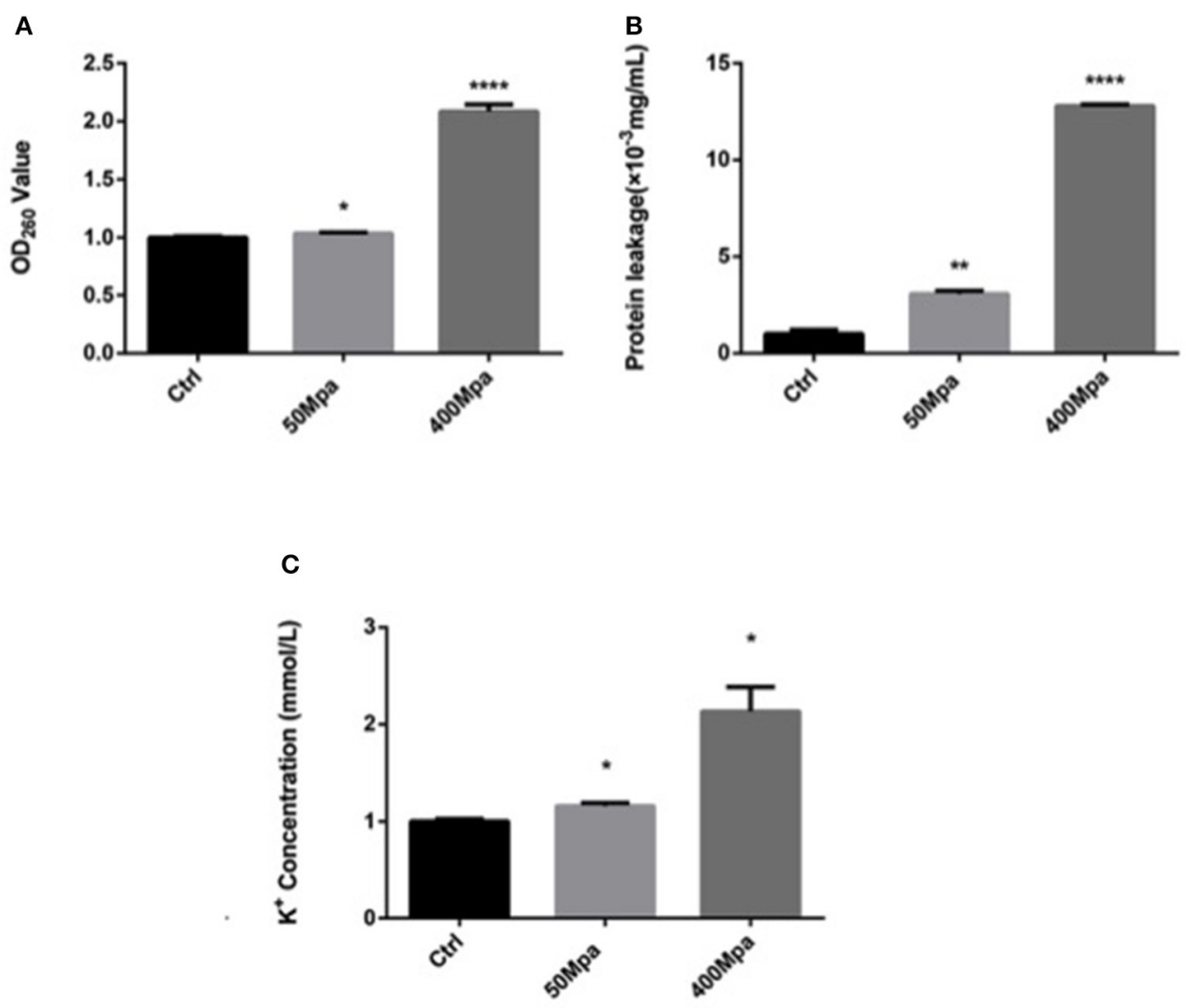

FIGURE 2 | Intracellular leakage after HHP treatment. (A) Nucleic acid leakage, (B) protein leakage, (C) potassium leakage. Asterisks indicate difference between control and different HHPs at ${ }^{*} P<0.05,{ }^{* *} P<0.01,{ }^{* \star *} P<0.001$, and ${ }^{* \star *} P<0.0001$.

could penetrate into the internal structure of the damaged cell membrane (13). As shown in Figure 1C, there is no detection of PI intracellular accumulation observed in both the control group and the 50-MPa-treated group, indicating live bacteria with integrated cell membrane. In the case of $400 \mathrm{MPa}$, most of the bacteria were stained red, implying that HHP led to incomplete outer and inner membranes, which is in agreement with the results of the plate counting method. Higher HHP treatment resulted in more damage in cell.

The survival changed with modified morphology, which is present in Figure 1B. The bacteria cell kept intact and the structure of cell was full under $50 \mathrm{MPa}$ conditions. However, the original structure of E. sakazakii cells treated with $400 \mathrm{MPa}$ was seriously damaged after inactivation, and it presented more pimples and swellings on the surface, and had an enlargement of electron-transparent regions in the bacterial cytoplasm. It indicated a damaged outer membrane of HHP-treated $E$. sakazakii, which was consistent with the results of Lee et al. (14), who found that HHP caused disruption of bacterial cell membrane and cell wall.

\section{Effect of HHP on Intracellular Leakage}

Figure 2 shows the leakage of DNA, intracellular protein, and $\mathrm{K}^{+}$ of E. sakazakii affected by the 50- and 400-MPa treatments. The 400-MPa treatment induced an obvious increase in intracellular protein release from 3.19 to $13.55 \mu \mathrm{g} / \mathrm{ml}$, while no significant changes were noted in the $50-\mathrm{MPa}$ group. A similar trend was also observed in the content of DNA and $\mathrm{K}^{+}$. Nucleic acid and protein are important in bacterial cell growth, while $\mathrm{K}^{+}$ affects cell internal balance (15). These intracellular leakages can be used as makers of cell membrane disruption. When the microorganism was exposed to severe environmental stress, the microbial cell membrane was destroyed, leading to different extents of loss of intercellular contents from the interior of the cell, cell lysis, and, finally, cell death.

\section{Effect of HHP on Key Cell Membrane Genes}

In order to understand the association of genotype to phenotype, three functional genes $(g l p K, p b p C$, and $o m p R)$ that correspond to the progress of cell membrane formation were quantified by qPCR (Figure 3). The RT-PCR analysis revealed that the transcript level of the membrane genes was downregulated by the HHP treatment in a significant way $(P<0.05$. Glycerol kinase $(g l p K)$ could catalyze the conversion of glycerol to glycerol-3-phosphate, the first step in glycerol catabolism, while $p b p C$ could contribute to the biogenesis of surface organelles by interaction with a patch of the cytoskeletal protein bactofilin. HHP reduced $g l p K$ and $p b p C$ activity, indicating lower glycerol utilization rate and outer membrane protein assembly, which 


\section{glpK}

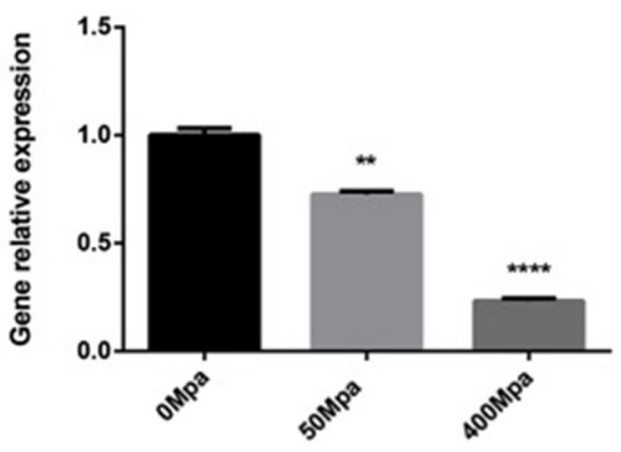

pbpc

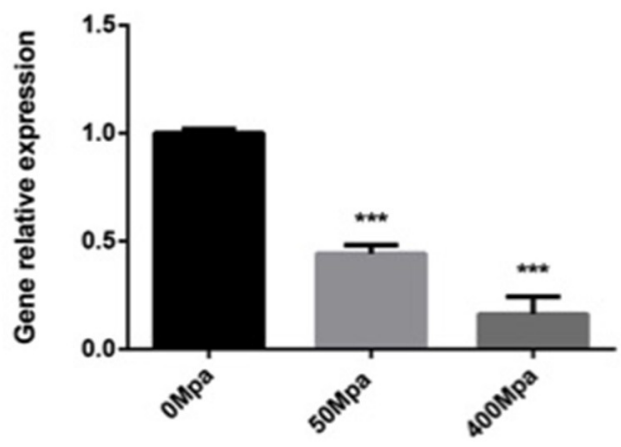

ompR

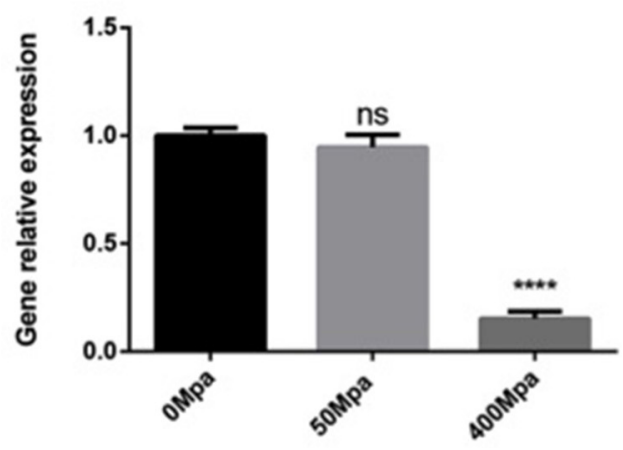

FIGURE 3 | Expression of selected cell membrane genes in E. sakazakii treated with HHP. Asterisks indicate difference between control and different HHPs at ${ }^{\star} P<$ $0.05,{ }^{\star \star} P<0.01,{ }^{\star \star \star} P<0.001$, and ${ }^{\star \star \star \star} P<0.0001$.

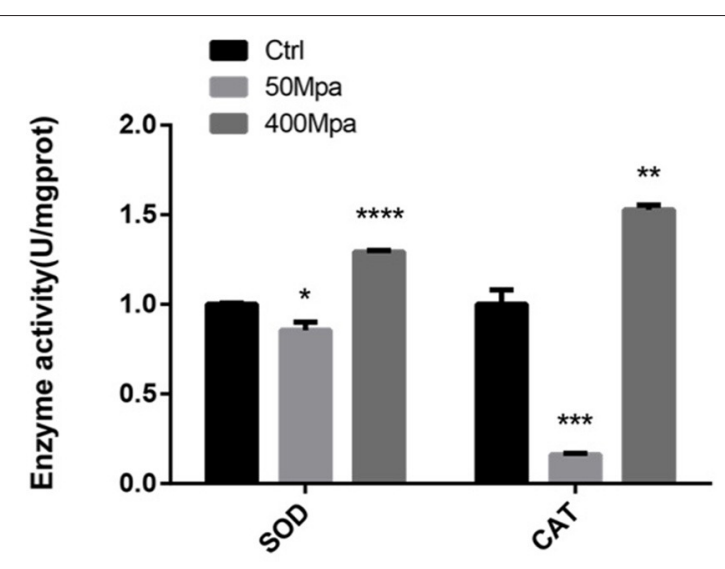

FIGURE 4 | Enzyme activity of superoxide dismutase (SOD) and catalase (CAT) of E. sakazakii with different pressures. Asterisks indicate difference between control and different HHPs at ${ }^{\star} P<0.05$, ${ }^{\star \star} P<0.01,{ }^{\star \star \star} P<0.001$, and ${ }^{\star \star \star \star} P<0.0001$.

was disadvantageous for cell growth. ompR is a response regulator in protecting cells against environmental stress through phosphorylation to elicit an adaptive response. The HHP treatment induced less $\operatorname{ompR}$ transcript in the E. sakazakii strain where it failed to repair damage caused by osmotic stress. This was consistent with the results observed in Gram-negative bacteria where the regulatory system of stress responses was triggered against limited conditions (16).

\section{Effect of HHP on Anti-oxidative Enzymes Activity}

The inhibitory action of HHP is mainly regarded as the generation of ROS in the bacterial cell. The major regulation of antioxidant levels contains superoxide dismutase (SOD) and catalase (CAT), or non-enzymatic antioxidants (17). Figure 4 shows the bacterial defense mechanisms against oxidative stress by HHP. The activity of SOD and CAT decreased at $50 \mathrm{MPa}$ from 83.61 and $120.27 \mathrm{U} / \mathrm{mg}$ prot to 71.54 and $19.41 \mathrm{U} / \mathrm{mg}$ prot, respectively. This suggested that the intracellular redox homostasis in E. sakazakii was broken by the HHP treatment (18). However, increasing the pressure showed an opposite trend. The 400-MPa treatment increased the activity of SOD and CAT to 108.72 and $183.77 \mathrm{U} / \mathrm{mg}$ prot, respectively. The initial inhibition of the SOD and CAT activity in the preliminary 50-MPa HHP 
treatment might be due to the limited conditions to make stress response for E. sakazakii. The bacteria had the ability to adapt and tolerate the lower pressure stimuli. When high pressure was applied, the enzyme activity was increased for bacterial oxidative stress response to external stimuli, which caused damage to the cells (19). Other studies have been conducted to analyze the endogenous intracellular oxidative stress in Escherichia coli and

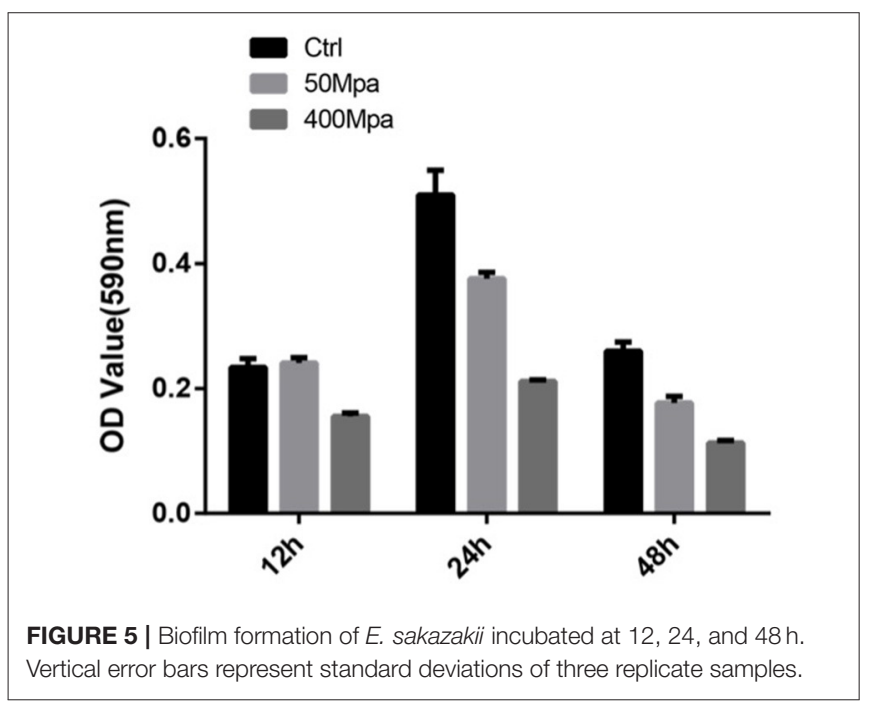

Mytilus galloprovincialis, which have shown an increase in the SOD and CAT activity when exposed to $\operatorname{HHP}(20,21)$.

\section{Effect of HHP on Biofilm Formation System}

Figure 5 show the biofilm-producing ability of E. sakazakii incubated at 12,24 , and $48 \mathrm{~h}$. After 24-h incubation, biofilm formation was increased while an opposite trend was observed at $48 \mathrm{~h}$. This could be attributed to the biofilm dispersion induced by starvation (22). When HHP was applied, the biofilmproducing ability was reduced. The quantity of biofilm was significantly decreased by $45 \%$ in the presence of $400 \mathrm{MPa}$ after 24-h incubation. This suggests that HHP could inhibit E. sakazakii cells from adhering to solid surfaces, which is in agreement with the cell membrane variations mentioned in sections of Intracellular Leakage. The biofilm-producing ability of E. sakazakii strains under different environmental stress conditions has been described previously in a number of studies (23).

The changed biofilm formation was controlled by their related virulence genes $(f l i H$, $f l i C$, $f l g I$, and $f l g K)$. As shown in Figure 6, it is found that the flagellin genes are increased at $50 \mathrm{MPa}$ and decreased at $400 \mathrm{MPa}$. FliC and FliD, two flagellar cap proteins, were present on the F1 gene locus of the flagellar regulon, while flgK and flgI coded for a hook-associated protein that stabilized the hook-filament junction together with $F \operatorname{lgL}(24)$. They were involved in the growth and diffusion of biofilm as a function of adhesion and colonization. The mRNA expression of biofilmrelated genes slightly increased after the low-pressure treatment

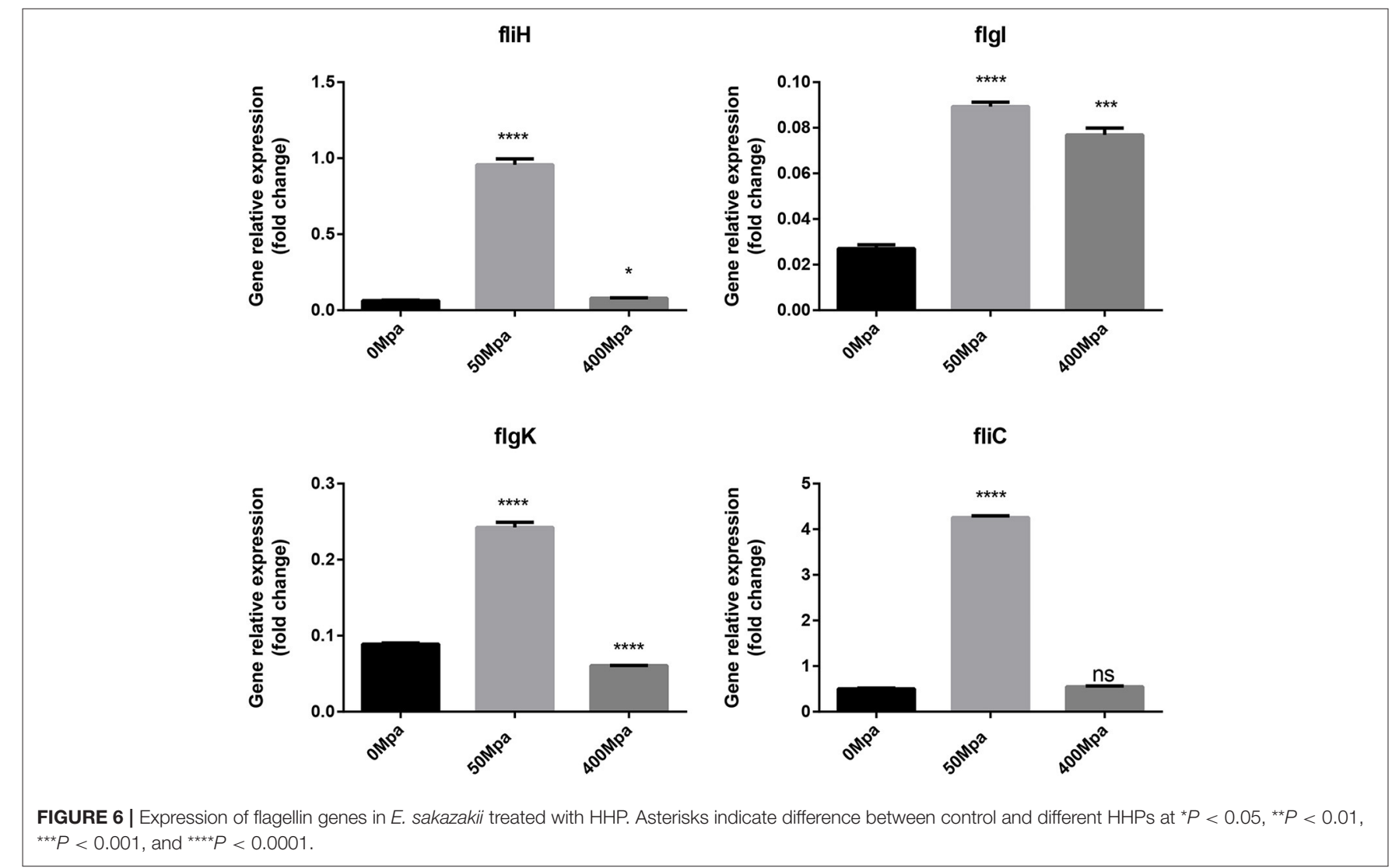


compared with the control, which could have contributed to bacterial chemotaxis. The flagellum synthesis in E. sakazakii was activated against poor environment for protection. However, the high-pressure conditions damaged the protection mechanism and resulted in loss of the ability to self-regulate.

\section{CONCLUSION}

In summary, HHP influenced cell membrane-related cell behaviors, such as metabolism utilization, outer membrane protein assembly, and stress responses in E. sakazakii. The variations in genotypes were reflected as lower level of cell membrane permeability, higher leakage of intracellular substances, and cellular deformations. Meanwhile, HHP increased bacterial oxidative stress response and disrupted biofilm formation by inhibiting cell adherence and extracellular matrix production. These findings will provide an understanding of the associations between bacterial genotype and phenotype induced by HHP.

\section{REFERENCES}

1. Kim KP, Klumpp J, Loessner MJ. Enterobacter sakazakii bacteriophages can prevent bacterial growth in reconstituted infant formula. Int J Food Microbiol. (2007) 115:195-203. doi: 10.1016/j.ijfoodmicro.2006.10.029

2. Ling N, Forsythe S, Wu Q, Ding Y, Zhang J, Zeng H, et al. Insights into Cronobacter sakazakii biofilm formation and control strategies in the food industry. Engineering. (2020) 6:393-405. doi: 10.1016/j.eng.2020.02.007

3. Townsend SM, Hurrell E, Gonzalez-Gomez I, Lowe J, Frye JG, Forsythe $\mathrm{S}$, et al. Enterobacter sakazakii invades brain capillary endothelial cells, persists in human macrophages influencing cytokine secretion and induces severe brain pathology in the neonatal rat. Microbiology. (2007) 153:3538-47. doi: 10.1099/mic.0.2007/009316-0

4. Edelson-Mammel SG, Porteous MK, Buchanan RL. Survival of Enterobacter sakazakii in a dehydrated powdered infant formula. J Food Protect. (2005) 68:1900-2. doi: 10.4315/0362-028X-68.9.1900

5. Perez MCP, Aliaga DR, Bernat CF, Enguidanos MR, Lopez AM. Inactivation of Enterobacter sakazakii by pulsed electric field in buffered peptone water and infant formula milk. Int Dairy J. (2007) 17:1441-9. doi: 10.1016/j.idairyj.2007.04.007

6. Lee JW, Oh SH, Byun EB, Kim JH, Kim JH, Woon JH, et al. Inactivation of Enterobacter sakazakii of dehydrated infant formula by gamma-irradiation. Radiat Phys Chem. (2007) 76:1858-61. doi: 10.1016/j.radphyschem.2007.02.105

7. Huang HW, Wu SJ, Lu JK, Shyu YT, Wang CY. Current status and future trends of high-pressure processing in food industry. Food Control. (2017) 72:1-8. doi: 10.1016/j.foodcont.2016.07.019

8. Gonzalez S, Flick GJ, Arritt FM, Holliman D, Meadows B. Effect of high-pressure processing on strains of Enterobacter sakazakii. J Food Protect. (2006) 69:935-7. doi: 10.4315/0362-028X-69. 4.935

9. Arroyo C, Cebrian G, Pagan R, Condón S. Synergistic combination of heat and ultrasonic waves under pressure for Cronobacter sakazakii inactivation in apple juice. Food Control. (2012) 25:342-8. doi: 10.1016/j.foodcont.2011.10.056

10. Koseki S, Matsubara M, Yamamoto K. Prediction of a required log reduction with probability for Enterobacter sakazakii during high-pressure processing, using a survival/death interface model. Appl Environ Microbiol. (2009) 75:1885-91. doi: 10.1128/AEM.02283-08

11. Jiao R, Gao J, Li Y, Zhang X, Zhang M, Ye Y, et al. Short communication: effects of high-pressure processing on the inactivity of Cronobacter sakazakii

\section{DATA AVAILABILITY STATEMENT}

The raw data supporting the conclusions of this article will be made available by the authors, without undue reservation.

\section{AUTHOR CONTRIBUTIONS}

QL: methodology and formal analysis. HT: investigation and writing-original draft preparation. YX: writing-review and editing. YL: visualization. H-LW: supervision and funding acquisition. All authors have read and agreed to the published version of the manuscript.

\section{FUNDING}

This study was supported by the National Key Basic Research Program of China (Grant Nos: 2018YFC1602201 and 2018YFC1602204) and the Fundamental Research Funds for the Central Universities (Grant No: JZ2020HGTB0043).

in whole milk and skim milk samples. J Dairy Sci. (2016) 99:7881-5. doi: 10.3168/jds.2016-11418

12. Yamin M, Souza AR, Castelucci BG, Mattoso JG, Bonafe CF. Synergism between high hydrostatic pressure and glutaraldehyde for the inactivation of Staphylococcus aureus at moderate temperature. Appl Microbiol Biotechnol. (2018) 102:8341-50. doi: 10.1007/s00253-018-9270-4

13. Zawadzka K, Bernat P, Felczak A, Rózalska S, Lisowska K. Antibacterial activity of high concentrations of carvedilol against gram-positive and gram-negative bacteria. Int J Antimicrob Agents. (2018) 51:458-67. doi: 10.1016/j.ijantimicag.2017.12.014

14. Lee YC, Tsai YH, Chen SL, Kung HF, Arakawa O, Wei CI. Inactivation and damage of histamine-forming bacteria by treatment with high hydrostatic pressure. Foods. (2020) 9:266. doi: 10.3390/foods9030266

15. Girgin Ersoy, Z, Barisci, S, Dinc, O. Mechanisms of the Escherichia coli and Enterococcus faecalis inactivation by ozone. LWT. (2019) 100:306-13. doi: 10.1016/j.lwt.2018.10.095

16. Cariri ML, de Melo ANF, Mizzi L, Ritter AC, Tondo E, de Souza EL, et al. Quantitative assessment of tolerance response to stress after exposure to oregano and rosemary essential oils, carvacrol and 1,8-cineole in Salmonella Enteritidis 86 and its isogenic deletion mutants $\Delta \mathrm{dps}, \Delta \mathrm{rpoS}$ and $\Delta \mathrm{ompR}$. Food Res Int. (2019) 122:679-87. doi: 10.1016/j.foodres.2019.01.046

17. Castro-Alférez M, Polo-López MI, Marugán J, Fernández-Ibáñez P. Mechanistic model of the Escherichia coli inactivation by solar disinfection based on the photo-generation of internal ROS and the photoinactivation of enzymes: CAT and SOD. Chem Eng J. (2017) 318:214-23. doi: 10.1016/j.cej.2016.06.093

18. Xu H, Zhu Y, Du M, Wang Y, Ju S, Ma R, et al. Subcellular mechanism of microbial inactivation during water disinfection by cold atmospheric-pressure plasma. Water Res. (2021) 188:116513. doi: 10.1016/j.watres.2020.116513

19. Wang J, Sui M, Yuan B, Li H, Lu H. Inactivation of two Mycobacteria by free chlorine: effectiveness, influencing factors, and mechanisms. Sci Tot Environ. (2019) 648:271-84. doi: 10.1016/j.scitotenv.2018.07.451

20. Aertsen A, De Spiegeleer P, Vanoirbeek K, Lavilla M, Michiels CW. Induction of oxidative stress by high hydrostatic pressure in Escherichia coli. Appl Environ Microbiol. (2005) 71:2226-31. doi: 10.1128/AEM.71.5.2226-2231.2005

21. Pinheiro M, Caetano M, Neuparth T, Barros S, Soares J, Raimundo J, et al. Ecotoxicology of deep-sea environments: functional and biochemical effects of suspended sediments in the model species Mytilus galloprovincialis under hyperbaric conditions. Sci Tot Environ. (2019) 670:218-5. doi: 10.1016/j.scitotenv.2019.03.196 
22. Liu H, Li S, Xie X, Shi Q. Pseudomonas putida actively forms biofilms to protect the population under antibiotic stress. Environ Pollut. (2021) 270:116261. doi: 10.1016/j.envpol.2020.116261

23. Santo D, Graca A, Nunes C, Quintas C. Escherichia coli and Cronobacter sakazakii in 'Tommy Atkins' minimally processed mangos: survival, growth and effect of UV-C and electrolyzed water. Food Microbiol. (2018) 70:49-54. doi: 10.1016/j.fm.2017.09.008

24. Jang MS, Mouri Y, Uchida K, Aizawa SI, Hayakawa M, Fujita N, et al. Genetic and transcriptional analyses of the flagellar gene cluster in actinoplanes missouriensis. J Bacteriol. (2016) 198:2219-27. doi: 10.1128/JB.00306-16

Conflict of Interest: The authors declare that the research was conducted in the absence of any commercial or financial relationships that could be construed as a potential conflict of interest.
Publisher's Note: All claims expressed in this article are solely those of the authors and do not necessarily represent those of their affiliated organizations, or those of the publisher, the editors and the reviewers. Any product that may be evaluated in this article, or claim that may be made by its manufacturer, is not guaranteed or endorsed by the publisher.

Copyright (C) 2021 Liao, Tao, Li, Xu and Wang. This is an open-access article distributed under the terms of the Creative Commons Attribution License (CC BY). The use, distribution or reproduction in other forums is permitted, provided the original author(s) and the copyright owner(s) are credited and that the original publication in this journal is cited, in accordance with accepted academic practice. No use, distribution or reproduction is permitted which does not comply with these terms. 